\title{
LEITURA E LETRAMENTO INFORMACIONAL NA UNIVERSIDADE: UM HIATO, UM CONSTRUTO FRAGMENTADO OU UM DILEMA?
}

\author{
LA LECTURA Y LA ALFABETIZACIÓN \\ INFORMACIONAL EN LA UNIVERSIDAD: UNA BRECHA, \\ UNA CONSTRUCCIÓN FRAGMENTADA O UN DILEMA?
}

\author{
Giordani Avila Reis* \\ Adriana Bogliolo Sirihal Duarte**
}

\begin{abstract}
RESUMO:
Introdução:Desde o surgimento da expressão information literacy no cenário educacional americano em 1974, observam-se diferentes modificações em suas características devido a evolução e aplicação ao longo dos anos. Em que se pesem os diferentes nomes que o novo conceito ganhou por aqui, verdade é que sua significação e aplicação encontram dificuldades para cumprir seu propósito. A transposição do conceito para um cenário diferente daquele em que foi concebido originariamente deveria sopesar as diferentes realidades econômicas, sociais e educacionais. Metodologia: $O$ artigo baseou-se numa revisão bibliográfica profunda de trabalhos já desenvolvidos na área da educação sobre a questão leitura e, na área da ciência da informação, sobre letramento informacional. Resultados e Conclusões: A leitura é o pilar principal do letramento informacional e é, também, a principal barreira que impede sua aplicação plena no contexto brasileiro. O problema da leitura acomete o indivíduo desde os níveis elementares de formação até a universidade, onde sua carência é visceralmente percebida. A indissociabilidade entre conceitos de alfabetização e letramento deveria possibilitar um estender de significações que garantisse a consecução do letramento informacional. Na verdade, os resultados observados na realidade dos índices pesquisados revelam que há uma parte faltante nesta equação que o letramento informacional parece não comportar.
\end{abstract}

Palavras-chave: Alfabetização. Letramento. Letramento informacional. Leitura.

\section{INTRODUÇÃO}

É por meio do domínio da leitura que o desenvolvimento e aprendizagem de todas as disciplinas curriculares se faz possível. Conforme pontuado em * Mestrando em Ciência da Informação. E-mail: reis.giordani@gmail.com

** Doutora em Ciência da Informação. Professora adjunta da Escola de Ciência da Informação da UFMG. E-mail: bogliolo.ufmg@gmail.com 
Weinberg e Edward (2005, p.72) o "melhor termômetro para aferir o grau de aprendizado de um estudante é, segundo os especialistas, sua capacidade de ler e interpretar um texto: quanto mais precária ela for, mais difícil será para ele absorver conhecimento em outras matérias".

Intrínseca e definitiva é a relação entre educação e desenvolvimento social. Independentemente da nomenclatura e do contexto abrangido pelo conceito utilizado, sociedade contemporânea, sociedade da informação, sociedade do conhecimento, sociedade do aprendizado, sociedade da tecnologia, entre outros, fato é que a força motriz capaz de romper a inércia e promover o movimento das engrenagens sociais é a educação.

Entretanto, o Programa Internacional de Avaliação de Estudantes (PISA) que acontece de três em três anos, avaliando a educação em nível médio (estudantes de aproximadamente 15 anos de idade), com abrangência em 65 países, desenvolvido e elaborado pela Organização para Cooperação e Desenvolvimento Econômico (OCDE) registrou, na última pesquisa realizada em 2012, considerações preocupantes sobre o cenário educacional brasileiro. Considere-se que, no Brasil, o PISA é coordenado pelo Instituto Nacional de Estudos e Pesquisas Anísio Teixeira (INEP).

Dentre os itens avaliados pelo PISA 2012, Leitura, Matemática e Ciências, o que nos interessa para a elaboração do presente artigo é o que trata a questão da leitura. Para tanto, o instituto informa que considerou a seguinte definição de letramento em leitura: "Letramento em leitura é a capacidade de compreender, utilizar, refletir e se envolver com textos escritos, com a função de alcançar uma meta, desenvolver seu conhecimento e potencial, e participar da sociedade" (OCDE, 2013).

Tendo caído 2 pontos de média, comparando-se 2009 a 2012, o Brasil ficou em $55^{\circ}$ lugar no ranking dos 65 países pesquisados. Do total de alunos participantes da pesquisa no Brasil, praticamente a metade (cerca de $49.2 \%$ ) tiveram média abaixo do nível 2 de proficiência em leitura, numa escala que mede de $1 \mathrm{~b}, 1 \mathrm{a}$ a 6 . Significa dizer que nossos alunos conseguem reconhecer, num texto familiar, o tema principal ou a intenção do autor. 
A falta de gosto pela leitura e a má formação do aluno aliados a questões outras, refletem a situação atual dos estudantes brasileiros. Fato é que se, conforme medido pelo PISA, o estudante do ensino médio no Brasil tem baixa proficiência em leitura, ao chegar no ambiente universitário, a situação mantém-se a mesma. Em 1983 Silva et al já chamavam a atenção para esta questão: "O estudante chega à Universidade despreparado para a prática de leitura compatível com o nível esperado. Resulta que, mesmo reconhecendo sua importância, a evita por insegurança; não sabe como ler e considera-se imaturo" (SILVA et al, 1983, p.31).

Uma vez na universidade, exige-se desse estudante não apenas a leitura crítica, mas o chamado letramento informacional: a capacidade de localizar a informação pertinente ao problema em questão a partir de diversas fontes, extraí-la, analisá-la criticamente, produzir sentido e comunicá-la. Destaca-se que o letramento informacional está inserido em um movimento de construção compartilhado com educadores e instituições de ensino, na busca de cumprimento de metas, formação de indivíduos e o desenvolvimento de profissionais e cidadãos, pois "[...] é algo trabalhado continuamente, observando, interpretando, compartilhando, questionando, elaborando críticas, hipóteses e explicações" (CAVALCANTE, 2006, p.57).

Deste modo, o presente artigo é fruto de pesquisa bibliográfica para dissertação de mestrado objetivando verificar como a questão da leitura vem sendo tratada pelo letramento informacional no ensino superior. Para a sua fundamentação realizou-se análise documental de artigos, textos científicos, teses, livros, dissertações, entre outros; tendo como público alvo todos os envolvidos no processo de ensino: docentes, discentes, pesquisadores, bibliotecários, entre outros.

\section{A IMPORTÂNCIA DA LEITURA}

A leitura é um divisor na vida de todo ser humano, pois abre um leque de novas descobertas, fomenta o crescimento pessoal que, consequentemente, reflete desde o convívio social até o desempenho acadêmico dos indivíduos.

Desde a criação da imprensa por Gutenberg, o ato de ler e as Inf. Inf., Londrina, v. 22, n. 3, p. 136 - 157, set../out. 2017. 
consequências possibilitadas por esse ato tornaram-se matéria prima essencial para as mudanças significativas da sociedade. Alguns autores citam haver duas eras distintas no cenário evolutivo humano: antes da escrita e depois da escrita. Um exagero talvez, mas profundamente exemplificativo da valoração que é devida à leitura.

Ler é viajar parado, é a possibilidade real de se locomover por vários lugares, sem sair do lugar; é, nos dizeres de Bamberger, ter um "ticket" atemporal:

Quando uma pessoa sabe ler bem, não existem fronteiras para ela. Ela pode viajar não apenas para outros países, mas também no passado, no futuro, no mundo da tecnologia, na natureza, no espaço cósmico. Descobre também o caminho para a porção mais íntima da alma humana, passando a conhecer melhor a si mesma e aos outros (BAMBERGER, 1987, p.29).

O ser humano é essencialmente um buscador de conhecimento. Paulo Freire, já assinalava que "a leitura do mundo precede sempre a leitura da palavra e a leitura desta, implica a continuidade da leitura daquela" (FREIRE, 2003, p.11).

Soares (1996) nos ensina que existem várias leituras possíveis de um mesmo texto, ou seja, o processo de leitura se traduz numa interação, numa formulação ativa que o sujeito acaba por produzir. As incursões nesse processo vão acontecendo de forma a estabelecer um diálogo entre o que se lê frente o arcabouço cultural do leitor. Desse diálogo resulta o processo de criação, pois o texto não é só um texto da mesma forma que a leitura não é só uma leitura, nem o leitor é só um leitor, mas o resultado de muitas possíveis leituras.

Moresi (2000, p.18), ao tratar do processo decisório em diferentes níveis de gestão, elenca quatro níveis hierárquicos, quatro classes diferentes de informação: dados >> informação >>> conhecimento >>> inteligência, que possibilitam tomadas de decisão, todos interligados, todos sendo transformados e ganhando maior relevância e importância a cada conclusão. 0 meio observado para se chegar aos resultados esperados na tratativa para transformação destes níveis passa necessariamente pela leitura, a boa leitura, 
uma leitura crítica e embasada, pois a cada atualização dos níveis, maior complexidade acaba demandando maior capacitação para o tratamento a ser dispensado.

Observa-se a inter-relação entre leitura, os níveis propostos por Moresi (2000) e a definição proposta pelo Instituto Nacional de Estudos e Pesquisas Educacionais Anísio Teixeira (INEP) para leitura enquanto “processo 'ativo', que "implica não apenas a capacidade para compreender um texto, mas a capacidade de refletir e de envolver-se com ele, a partir de ideias e experiências próprias" (INEP, 2012, p. 21).

Difundir o ensino e a aprendizagem não é empreitada das mais simples, demanda uma austeridade ressaltada por uma cadeia sequencial de metodologias e políticas que devem ser adotadas para que seja possível chegar a um nível de aprimoramento que permita aos alunos o desenvolvimento natural do conhecimento.

Menegassi e Ângelo (2005, p. 40) afirmam que "é fundamental ao professor saber quais os conceitos de leitura que perpassam o sistema educacional brasileiro, para poder identificar e saber orientar o aluno de maneira adequada na construção da leitura". Nesse sentido, é necessário entender o espaço Escola enquanto espaço destinado à mediação. A formalidade estrutural do ensino deve conviver com os avanços advindos das novas tecnologias, a letargia provocada pelo inequívoco monopólio da informação e todo 'poder' dele decorrente deve dialogar com as singularidades pessoais dos alunos, possibilitando processos mais humanos de transmissão de saberes que, por sua vez, possibilitem e estimulem o aprendizado de forma continuada, interessada, essencialmente necessária para a construção de uma sociedade cada vez mais evoluída.

Nos dizeres de Dionísio (2000, p.44) a escola deve ser entendida como "espaço ideal para a estruturação de uma comunidade leitora cuja ação ultrapassará sempre os muros bem delimitados da instituição". Ler é essencial e fomentar a leitura é tarefa de todos os envolvidos no processo educacional. 
Através da leitura aumenta-se a chance das oportunidades sociais serem mais abrangentes e democráticas. Segundo Justino:

Quando a escola conseguir assumir a responsabilidade de contrariar o determinismo social do insucesso, então estaremos no bom caminho no sentido da concretização do princípio da equidade e da igualdade de oportunidades. Enquanto não o conseguirmos, seremos sempre confrontados com a ineficácia do sistema de ensino ao não cumprir a missão que lhe está confiada (JUSTINO, 2012, p.65).

O processo de aprendizagem e a formação cultural do indivíduo vão muito além do simples repasse de informação; exigem métodos, técnicas, procedimentos e instrumentos adequados para que se obtenham resultados condizentes com as singularidades e expectativas de cada grupo.

\section{LEITURA: NAVEGANDO ENTRE CONCEITOS DE ALFABETIZAÇÃO E LETRAMENTO.}

Buscando entender as modificações, adaptações e ampliações sofridas pelo conceito de alfabetização na recente história da educação brasileira, norteando nossa reflexão em direção ao momento em que o todo deixou de ser todo e passou a ser parte de um "novo processo", o letramento, ressaltamos que tais conceitos, nada mais são do que palavras familiares, de uso comum, habituais, exceto quiçá letramento, conceito ainda não inteiramente abrangido, talvez, por ter sido inserido há pouco no nosso habitual.

A alfabetização não deixa de ser um tema recorrente cuja relevância abrange todas as etapas de vida do indivíduo. Seja pela sua importância social, seja pela magnitude do poder que o conceito engloba, seja pela impossibilidade semântica de limitar a gama de possibilidades que o mesmo provoca. Apesar da obviedade do fato, vale ressaltar que educação é para toda a vida, não se perde, não deveria se deteriorar, não deveria bastar; é um processo que se renova a cada nova leitura, a cada nova compreensão e sentido dado a um novo e até mesmo velho texto, nos processos de releitura, no processo de aprimoramento pessoal e individual, refletindo-se na evolução gradativa individual e, consequentemente, social. 

fragmentado ou um dilema?

É vital a definição de alfabetização como o processo de ensino das letras. É entre tantas coisas a possibilidade de tornar o indivíduo capaz de ler e escrever, é retirar do indivíduo as cortinas, o manto que lhe cerceia a luz, é darIhe mais que oxigênio, é fazê-lo sentir o prazer da inspiração, é permitir-lhe capacidades tais que possa criar suas próprias asas e voar, livre, leve e solto, é torná-lo senhor das suas vontades.

A importância do tema reflete-se internacionalmente. Em 1997, a UNESCO durante a $V$ Conferência Internacional de Educação para Jovens Adultos, postulou o seguinte conceito sobre alfabetização:

A alfabetização, concebida como conhecimento básico e habilidades necessárias a todos num mundo em rápida transformação, é um direito humano fundamental. Em toda sociedade, a alfabetização é uma habilidade primordial em si mesma e um dos pilares para o desenvolvimento de outras habilidades. Existem milhões de pessoas - a maioria mulheres - que não têm a oportunidade de aprender nem mesmo de se apropriar desse direito. O desafio é oferecer-lhes esse direito. Isso implica criar pré-condições para a aprendizagem por meio da conscientização e do empoderamento. A alfabetização é também um catalisador para a participação em atividades sociais, culturais, políticas e econômicas, e para a aprendizagem ao longo da vida (UNESCO, 1998, p.5).

Já o termo letramento foi utilizado pela primeira vez em 1986, por Mary Kato em seu livro "No Mundo da Escrita: uma perspectiva psicolinguística", sendo em seguida adotado por pesquisadores da área da educação.

[...] a função da escola, na área da linguagem, é introduzir a criança no mundo da escrita, tornando-a um cidadão funcionalmente letrado, isto é, um sujeito capaz de fazer uso da linguagem escrita para sua necessidade individual de crescer cognitivamente e pra atender às várias demandas de uma sociedade que prestigia esse tipo de linguagem como um dos instrumentos de comunicação. Acredito ainda que a chamada norma-padrão, ou língua falada culta, é consequência do letramento, motivo por que indiretamente, é função da escola desenvolver no aluno o domínio da linguagem falada institucionalmente aceita (KATO, 1986, p.7).

Observa-se que o conceito de letramento, no Brasil, ganhou uma significação que o diferencia da alfabetização. Segundo a Profa. Magda Soares, origina-se da tradução do termo em inglês literacy, cujo significado é: 
"o resultado da ação de ensinar ou de aprender a ler e escrever: o estado ou a condição que adquire um grupo social ou um indivíduo como consequência de ter-se apropriado da escrita" (SOARES, 2004b, p.18).

Literato ou letrado é, portanto, um adjetivo que diferencia a pessoa que domina a leitura e a escrita. Já letramento, por sua vez, caracteriza o indivíduo que é letrado, ou seja, aquele que não somente sabe ler e escrever, mas também o faz de forma cognitivamente competente, respondendo satisfatoriamente às exigências sociais da prática da leitura e da escrita, observando-se nesse contexto semântico o caráter e peculiaridades inerentes ao agente enquanto protagonista.

A autora ressalta que, embora sejam conceitos diferentes, estão associados (embora um não implique no outro, como veremos adiante):

"[...] dissociar alfabetização de letramento é um equívoco porque, no quadro das atuais concepções psicológicas, lingüísticas e psicolingüísticas de leitura e escrita, a entrada da criança (e também do adulto analfabeto) no mundo da escrita se dá simultaneamente por esses dois processos: pela aquisição do sistema convencional de escrita - a alfabetização, e pelo desenvolvimento de habilidades de uso desse sistema em atividades de leitura e escrita, nas práticas sociais que envolvem a língua escrita - o letramento. Não são processos independentes, mas interdependentes, e indissociáveis: a alfabetização se desenvolve no contexto de e por meio de práticas sociais de leitura e de escrita, isto é, através de atividades de letramento, e este, por sua vez, só pode desenvolver-se no contexto da e por meio da aprendizagem das relações fonema/grafema, isto é, em dependência da alfabetização" (SOARES, 2004a, p.10).

Ainda de acordo com Soares (2009) letramento surge como uma necessidade para se abarcar uma nova situação:

$\mathrm{Na}$ impossibilidade de determinar que a palavra alfabetização passe a significar, não só a aprendizagem do sistema alfabético, mas também a aprendizagem dos usos sociais e culturais desse sistema, é que a "invenção" da palavra letramento tornou-se necessária (SOARES, 2009, p.7).

A leitura é matéria prima para construção do conhecimento pessoal devendo ser entendida como um ato distinto envolvendo o compreender e a 
Leitura e letramento informacional na universidade: um hiato, um construto fragmentado ou um dilema?

compreensão. Tanto é verdade que podemos observar que o mundo é dominado pela palavra escrita, seja ela impressa, seja ela inserida de forma televisiva, ou ainda, postada digitalmente.

Carvalho e Mendonça (2006) na introdução ao primeiro capítulo da coletânea de artigos intitulado "Práticas de letramento e processos de alfabetização", esclarecem os conceitos de forma irremediavelmente pontual:

O letramento pode ser considerado um processo complexo, que quase sempre é visto como associado à alfabetização. Contudo, existem letramentos de natureza variada, inclusive, sem a presença da alfabetização. Trata-se de um termo que é conceituado de modo diferente por autores que estudam o fenômeno; mas, em suma, pode-se dizer que o letramento é um processo histórico-social.

É de compreensão razoável, portanto, que o letramento influencie até mesmo culturas e indivíduos que não dominam a escrita, pois se trata de um processo mais amplo do que a alfabetização, embora esteja intimamente relacionado à existência de um código escrito. Assim, culturas ou indivíduos que podem ser considerados ágrafos ou iletrados são somente aqueles que vivem em uma sociedade que não possui, nem sofre, a influência, mesmo que indireta, de um sistema de escrita. Por esta razão, pode-se afirmar que não existe uma relação direta entre escolaridade e letramento, embora a escolarização possibilite uma inserção mais democrática do sujeito nas sociedades letradas.

O letramento abrange a capacidade de o sujeito colocar-se como autor (sujeito) do próprio discurso, no que se refere não só à relação com o texto escrito, mas também à relação com o texto oral. Logo, para uma concepção histórico-social do letramento, há de se considerar uma concepção de língua - e de linguagem - constitutiva das ações sociais. Ações que se organizam em enunciados que se criam e se recriam nas práticas comunicativas, configurando os variados gêneros e seus suportes, os quais podem ser vistos como o resultado das práticas discursivas convencionadas e institucionalizadas de comunidades discursivas específicas (CARVALHO; MENDONÇA, 2006, p.10).

Corroborando com o posicionamento acima, Magda Soares, já citada, considerada um dos expoentes no estudo do letramento no Brasil, enfatiza a diferença entre os conceitos de letramento e alfabetização da seguinte forma:

Uma última inferência que se pode tirar do conceito de letramento é que o indivíduo pode não saber ler e escrever, isto é, ser analfabeto, mas ser, de certa forma, letrado (atribuindo a 
este adjetivo sentido vinculado a letramento). Assim, um adulto pode ser analfabeto, porque marginalizado social e economicamente, mas, se vive em um meio em que a leitura e a escrita têm presença forte, e se interessa em ouvir a leitura de jornais feita por um alfabetizado, se recebe cartas que os outros lêem para ele, se dita cartas para que um alfabetizado as escreva (e é significativo que, em geral, dita usando vocabulário e estruturas próprios da língua escrita), se pede a alguém que the leia avisos ou indicações afixados em algum lugar, esse analfabeto é, de certa forma, letrado, porque faz uso da escrita, envolve-se em práticas sociais de leitura e de escrita (SOARES, 2004a, p.24).

Da análise acima depreende-se, portanto, que um indivíduo alfabetizado não tem que ser necessariamente um indivíduo letrado, e que, um indivíduo letrado não tem de ser necessariamente um indivíduo alfabetizado. Em outras palavras, não se trata de uma simples questão semântica, mas um estender de conceitos, conceitos que se interagem e se completam, que não são similares nem antagônicos, que são independentes, mas são indubitavelmente mais ricos quando apresentados de forma conexa.

O termo alfabetizado, no Brasil, tem caráter institucional e político, pois oficialmente, qualquer pessoa que consiga ler e assinar seu nome, ainda que de forma rudimentar é considerada alfabetizada.

Historicamente, esta assertiva foi muito bem observada nos trabalhos da já citada Professora Magda Soares (1996, 2004a e 2004b). Segundo a autora (2004b), em 1940, para ser considerada alfabetizada uma pessoa deveria saber escrever o próprio nome.

Se em 1958 a UNESCO entendia o conceito de alfabetizado como sendo aquele em que o indivíduo seria capaz de ler ou escrever um enunciado simples, relacionado à sua vida diária, em 1978, a mesma entidade adota o termo alfabetização funcional,

[...] qualificando de funcional quando suficiente para que os indivíduos possam inserir-se adequadamente em seu meio, sendo capazes de desempenhar tarefas em que a leitura, a escrita e o cálculo são demandados para seu próprio desenvolvimento e para o desenvolvimento de sua comunidade.

O qualitativo funcional insere a definição do alfabetismo na perspectiva do relativismo sociocultural. Tal definição já não visa limitar a competência ao seu nível mais simples (ler e 
escrever enunciados simples referidos à vida diária), mas abrigar graus e tipos diversos de habilidades, de acordo com as necessidades impostas pelos contextos econômicos, políticos ou socioculturais" (RIBEIRO, 1997, p.147).

Para Ribeiro o termo alfabeto funcional é tão somente um indicador de insuficiência de escolarização. Todavia, se o termo pode ser entendido como indicador, os dados apresentados por Batista (2006), tendo como fonte a pesquisa realizada pelo Instituto Nacional de Estudos e Pesquisas Educacionais Anísio Teixeira (INEP), em parceria com o Programa Internacional de Avaliação de Estudantes (PISA) e desenvolvida pela Organização para a Cooperação e Desenvolvimento Econômico (OCDE), se mostram alarmantes:

De acordo com os dados do PISA, a proficiência em leitura de estudantes brasileiros de 15 anos é significativamente inferior à de todos os outros países da avaliação. De acordo com os dados do SAEB, na avaliação realizada em 2001 (divulgada em 2003) 2 , apenas $4,48 \%$ dos alunos de $4^{\text {a }}$ série possuem um nível de leitura adequado ou superior ao exigido para continuar seus estudos no segundo segmento do Ensino Fundamental.

Uma parte deles apresenta um desempenho situado no nível intermediário, 36,2\%, segundo o SAEB, estão 'começando a desenvolver as habilidades de leitura, mas ainda aquém do nível exigido para a $4^{a}$ série'. A grande maioria se concentra, desse modo, nos estágios mais elementares de desenvolvimento, $59 \%$ dos alunos da $4^{a}$ série apresentam acentuadas limitações em seu aprendizado de leitura e escrita. Dito de outra forma, cerca de $37 \%$ dos alunos estão no estágio crítico de construção de suas competências de leitura, o que significa que têm dificuldades graves para ler, e $22 \%$ estão abaixo desse nível, no estágio muito crítico, o que significa que não sabem ler. (BATISTA, 2006, p.14).

Seguindo por esta linha de entendimento o Instituto Brasileiro de Geografia e Estatística (IBGE), entende por analfabeto funcional aquele indivíduo que têm menos de quatro anos de estudos completos. De acordo com os dados da instituição, o índice de analfabetos funcionais em 2011 era de $20,4 \%$ da população com 15 ou mais de idade.

Cogitando que a permanência dos alunos em escolas, dadas às dificuldades do sistema de ensino, não lhes garantam a alfabetização plena, o índice acima tende a aumentar, consideravelmente. 

fragmentado ou um dilema?

Já as definições propostas pelo Indicador Nacional de Alfabetismo Funcional (INAF) objetivam apresentar, por meio de pesquisas em âmbito nacional, uma análise mais realista do contexto educacional brasileiro, caracterizando o analfabetismo da seguinte forma:

1. Analfabetismo: não domina as habilidades medidas;

2. Alfabetismo Nível Rudimentar: localiza uma informação simples em enunciados de uma só frase, um anúncio ou chamada de capa de revista, por exemplo;

3. Alfabetismo Nível Básico: localiza uma informação em textos curtos ou médios, mesmo que seja necessário realizar inferências simples;

4. Alfabetismo Nível Pleno: localiza mais de um item de informação em textos mais longos, compara informação contida em diferentes textos, estabelece relações entre as informações (causa/efeito, regra geral/caso, opinião/fato). Reconhece a informação textual mesmo que contradiga o senso comum. (CRUZ; MONTEIRO, 2013, p.71).

O estudo avalia os últimos 100 anos do cenário brasileiro, ressaltando o grande progresso desde então: "a taxa de analfabetismo na população de 15 anos ou mais caiu de forma constante ao longo do século passado, saindo de um patamar de 65,3\% em 1900 para chegar a 13,6\% em 2000" (CRUZ; MONTEIRO, 2013, p. 73). Se a evolução é grande e mostra um lado otimista, por outro lado os números absolutos ainda são assustadores, uma vez que o alfabetismo pleno medido em 2011 e apresentado neste mesmo documento ( $p$. 71 ) é de tão somente $26 \%$ da população brasileira. Além disso, é apresentada a extrema desigualdade do nível de alfabetização entre as diferentes regiões brasileiras. Finalmente, de acordo com o anuário, "No Brasil, 11\% dos adultos entre 35 e 44 anos completaram a Educação Superior, segundo dados da publicação Education at a Glance 2010, da OCDE. No Chile, este percentual é de 27\%, e nos Estados Unidos chega a 43\%" (CRUZ; MONTEIRO, 2013, p. 83).

Os dados revelam uma faceta conhecida e alarmante do nosso sistema de ensino, por ratificarem que apenas um quarto da população brasileira pode ser considerada plenamente alfabetizada. 


\section{LETRAMENTO INFORMACIONAL NA UNIVERSIDADE}

A linha de pesquisa, fonte do presente artigo, Leitura e letramento informacional na universidade: um hiato, um construto fragmentado ou um dilema? se estabeleceu a partir de questão inerente à base do letramento informacional, a leitura, que esbarra na falta crônica de um leitor crítico no meio acadêmico e como os múltiplos contornos da falta de leitura são reconhecidos pelo letramento informacional.

A realidade para aqueles que têm dificuldades com a leitura, em compreender, assumir um olhar crítico, expressar e se colocar, mostra-se cada vez mais complexa conforme já pontuava Barros (1986):

[...] o bibliotecário que não lê se castra consciente ou inconscientemente. Não avança e não promove conhecimento. Não se arma para os imprevistos do dia a dia, esquecendo-se que a biblioteca e a universidade são palcos de incontáveis dúvidas que sua cultura pode ajudar a resolver. Sendo o bibliotecário um profissional da informação, por excelência, não pode, ele próprio, estar alheio aos fatos e às notícias. É essa constante atualização do conhecimento, repito, que faz do seu referencial teórico uma base segura de apoio ao leitor a que está vinculado [...] (BARROS, 1986, p.30).

Entendemos que a relação entre leitura, aprendizagem, bibliotecas, bibliotecários e letramento informacional no ambiente acadêmico deveria ter uma dinâmica natural, pois sua defasagem pode ter como implicações:

- deficiência de linguagem, gerando inadequação na construção textual;

- problemas de compreensão e produção de textos que comprometem o desempenho acadêmico do universitário;

- isolamento, provocando o desinteresse;

- desinteresse, ocasionando o abandono;

- distanciamento do que é pretensamente aludido (inclusão social) da realidade (exclusão social);

- formação de baixa qualidade, em última análise.

Nesse contexto, o conceito de letramento informacional no cenário estudantil universitário deveria ter seu papel mais intimamente ligado à questão 
educacional. Entretanto, conforme destaca Campello, "[...] apesar de calcado em pretensa parceria com os educadores, o conceito continua limitado à literatura de biblioteconomia e ciência da informação" (CAMPELLO, 2003, p.36).

Ademais, se observa que a produção acadêmica sobre letramento informacional e educação pode ser considerada incipiente (GASQUE, 2010, p.88).

O avanço tecnológico, propiciando uma infinita disponibilidade de recursos informacionais, nem sempre aproveitável, vem evidenciando de forma mais enfática o problema da leitura (seja pela falta, seja pelo excesso e dificuldade de seleção, seja pela qualidade, seja pelo despreparo dos envolvidos no processo) no ensino superior.

Considerando-se a leitura uma ação efetiva e indispensável para a qualidade do desempenho do estudante do ensino superior, essa necessidade guarda maior relevância devido seu alcance e sua diversidade.

Witter (1997) chama a atenção para a importância da leitura para o ensino universitário:

[...] a leitura é um comportamento essencial para o ensino aprendizagem no ensino superior. É a última oportunidade para tornar o cidadão um leitor competente, crítico, frequente, criativo, que compreende e usa de forma adequada às informações obtidas via texto (WITTER, 1997, p. 11).

A autora continua:

"[...] certamente as contingências de vida anterior ao ingresso na Universidade, o nível de desempenho em leitura com que nela ingressa e as condições atuais de vida do estudante são variáveis que influem na leitura do universitário" (WITTER, 1997, p. 11).

Diante deste analfabetismo funcional constatado no cenário brasileiro, Lajolo (2010, p.108) afirma que o professor "precisa gostar de ler muito, precisa envolver-se com o que lê", porque, se assim não for, dificilmente conseguirá formar alunos críticos e autônomos pois, provavelmente, não estabelecerão gosto pela leitura e não serão capazes de assimilar que a compreensão é a base da leitura. 

fragmentado ou um dilema?

Para níveis distintos de exigência, níveis distintos de leitores. Pensando no universo acadêmico consideramos que mais e mais complexas são as relações envolvendo textos, informação e saberes. Esse universo exige níveis mais proficientes de leitores, cujas capacidades cognitivas, interpretativas, Ihes possibilitem o agir enquanto protagonistas no processo de desenvolvimento cultural, no enriquecer do conhecimento e na capacitação pessoal, social.

A busca por uma real dimensão da relevância da leitura para o universo do ensino superior nos transporta a uma inevitável análise das práticas intrínsecas ao agir pedagógico e nos remete aos quatro pilares norteadores da educação superior, instituídos pela Comissão Internacional sobre a Educação para o Século XXI e introduzidos ao relatório da UNESCO: aprender a conhecer, aprender a fazer, aprender a viver juntos e aprender a ser. De acordo com Rios:

(...) o saber fazer bem tem uma dimensão técnica, a do saber e do saber fazer, isto é, do domínio dos conteúdos de que o sujeito necessita para desempenhar o seu papel, aquilo que se requer dele socialmente, articulado com o domínio das técnicas, das estratégias que permitam que ele, digamos, "dê conta de seu recado" em seu trabalho (RIOS, 1999, p.47).

Nesse contexto, podemos afirmar que para se trabalhar com estudantes proficientes no ensino superior, necessário se faz criar mecanismos de aperfeiçoamento e valoração da capacidade de compreender e produzir textos. Em contraponto, o que são retratadas nas pesquisas realizadas são metodologias contraproducentes que emergem de ultrapassadas práticas para o ensino da leitura, acabando por promoverem um círculo vicioso em decorrência da tentativa de transferência de responsabilidades na esfera da docência.

Citando Alves (2007):

Existe um ciclo vicioso de responsabilidade no ensino da leitura na escola. Em geral, os professores das séries iniciais acusam os pais por não colaborarem no processo da leitura, os professores das séries seguintes, por sua vez, acusam os anteriores.

A Universidade culpa os professores de ensino médio que ela própria formou pela falta de habilidades que muitos estudantes apresentam no desenvolvimento da leitura. Enfim, é cada um 


\title{
passando a responsabilidade pela deficiência de leitura dos
} estudantes (ALVES, 2007, p. 03).

Silva ainda destaca outros fatores que comprometem o currículo universitário:

\begin{abstract}
"Pouca importância atribuída às disciplinas pedagógicas [...]; Falta de integração entre as disciplinas [...]; Redução do ato pedagógico à leitura e discussão de textos [...]; Vício ou dependência de apostilas (ou de cópias xérox) contendo apenas o "essencial" para consumo rápido [...]; Apego exagerado a um único tipo de organização de texto, o técnico ou teórico [...] (SILVA, 1999, p. 89-90).
\end{abstract}

Assim, dentre todas as dificuldades mencionadas, a que causa maior distanciamento entre teoria e prática, entre desejo e realidade, entre factível e possível, é a deficiência de leitura, principalmente no meio acadêmico.

Neste sentido, julga-se importante destacar as facetas das necessidades humanas apresentadas pela Teoria de Maslow, para quem tais necessidades satisfazem a uma hierarquia, uma grandeza de valores a serem galgadas e, é esta hierarquia que determina o comportamento, os estímulos, a motivação, desempenho e satisfação dos indivíduos.

Assim, de acordo com Maslow (1971), a partir do momento em que uma necessidade surge, surgem também estímulos motivadores que desencadeiam um processo cujo objetivo é a satisfação desta necessidade. Esse processo nunca termina, temos um continuum, que pode assim ser entendido: tão logo uma necessidade é satisfeita, ou até mesmo, tão logo uma fase da pirâmide seja satisfeita, uma nova necessidade surge, um novo desafio, uma nova conquista, outro degrau, um novo patamar.

Ainda de acordo com o autor, a premissa para a satisfação é o avanço que só pode ser verdadeiro e libertador uma vez cumpridas às exigências das necessidades anteriores, em outras palavras, não há que se falar em novas necessidades, em avanços, sem que as necessidades anteriores tenham sido transpostas.

Na elaboração de sua teoria, Maslow considerou que sua composição levasse em conta a disposição em níveis e fosse retratada a importância e influência de cada um desses níveis, desde a base até o topo da hierarquia. 0 
autor trata, portanto, da importância dos fins, que é a satisfação das necessidades dos indivíduos.

Segundo Maslow, satisfeita uma necessidade galga-se um novo nível hierárquico e nova necessidade emerge. Assim, o indivíduo só vai procurar conhecimento se houver necessidade. Nesse prisma, não há conhecimento pleno, não há letramento pleno, não há informação que abarque o saber de forma plena, pois é da natureza humana o constante buscar. O conhecimento provoca a necessidade de mais conhecimento agindo como um fator multiplicador e estimulante.

Consideramos, portanto, que a dificuldade em ler e interpretar textos vivenciada no ensino superior é a mola propulsora da teoria demonstrada por Maslow, qual seja, a necessidade a ser saciada e o conhecimento a ser alcançado. Desta forma, faz-se necessário trabalhar a base satisfazendo as necessidades primárias de educação e formação do indivíduo, buscando evitar um retroagir, ou ainda pior, um galgar inseguro na pirâmide, o que significa um retrabalho, dispêndio de energia e tempo.

\section{CONSIDERAÇÕES FINAIS}

No livro Retratos da Leitura no Brasil 3, organizado por Failla, o leitor é definido como "aquele que leu, inteiro ou em partes, pelos menos 1 livro nos últimos 3 meses" (FAILLA, 2012, p. 47). Ainda de acordo com a pesquisa, o número de livros lidos por ano (dados colhidos em 2011 em todo território nacional) foi de 4 livros por habitante, sendo que desse total apenas 2.1 foram lidos inteiramente e 2.0 foram lidos em partes (FAILLA, 2012, p.71). Podemos observar a nossa péssima qualidade de leitores. A informação de que simplesmente não lemos, melhor dizendo, lemos muito pouco e com pouca qualidade não é nova.

Essa realidade que traz instabilidade social é o que acontece na análise do nosso caso. O aluno universitário não viu satisfeita a necessidade relacionada à questão da leitura durante sua formação de base, mas, ainda assim, contrariando as expectativas de trajetória e graduação desejada, ele 
perseverou galgando degraus e causando uma ruptura significativa em sua base.

Dada a urgência do tema e sua relevância, percebe-se que é imperativa a reflexão sobre capacidade de leitura enquanto justificativa para o sucesso ou insucesso dos estudantes no ensino superior.

Por meio do referencial teórico aqui analisado resta evidenciado que a situação da leitura no Brasil é caótica, ficando, praticamente, à margem do mínimo satisfatório proposto por várias entidades nacionais e pesquisas internacionais. Observamos ainda que o comprometimento na formação escolar que antecede à Universidade promove um distanciamento cada vez maior entre o que é desejado e a realidade que é vivenciada no universo acadêmico.

O letramento informacional é fundamental para que os indivíduos reconheçam as informações necessárias, aperfeiçoem suas habilidades enquanto leitores críticos e justifiquem o uso das informações por meio de novos conhecimentos adquiridos e gerados. Conforme dito anteriormente, é fundamental que se considere existir níveis de leitura, assim como níveis de letramento.

Então temos o seguinte dilema: Como pode o letramento informacional dar tratamento à questão "falta de leitura no ensino superior" se a leitura é fundamento, condição sine qua non, a base do letramento informacional?

Novas ferramentas sociais, desconstrução de conceitos, investimentos massivos em educação, políticas públicas factíveis talvez, pensadas e trabalhadas a longo prazo, sejam capazes de solucionar o agora, inconteste dilema. 


\section{REFERÊNCIAS}

ALVES, A. L. M. S. Leitura e Universidade: comportamento de leitura na formação do pedagogo da UFPA. In: SIMPÓSIO BRASILEIRO/V CONGRESSO LUSOBRASILEIRO / I COLÓQUIO IBERO-AMERICANO, 23. Porto Alegre. Por uma Escola de Qualidade para Todos. Anais. Porto Alegre: UFRGS/FEFED/PPGEDU, v. 1. p. 1-15., 2007.

BAMBERGER, R. Como incentivar o hábito da leitura. São Paulo: Ática, 1987.

BARROS, M. H. T. C. O bibliotecário e o ato de ler. In: SILVA, E. T. (Org.). O bibliotecário e a análise dos problemas de leitura. Porto Alegre: Mercado Aberto, 1986. (Cadernos da ALB, 1).

BATISTA, A. A. G. Alfabetização, leitura e escrita. In: CARVALHO, Maria A. F. \& MENDONÇA, Rosa H. (org.). Práticas de leitura e escrita. Brasília: Ministério da Educação, 2006. p. 13-17.

CAMPELLO, B. S. O movimento da competência informacional: uma perspectiva para o letramento informacional. Ciência da Informação, Brasília, v.2, n.3, p.28-37. set./dez. 2003.

CAREGNATO, S. E. O desenvolvimento de habilidade informacionais: o papel das bibliotecas universitárias no contexto da informação digital em rede.

Revista de Biblioteconomia \& Comunicação, Porto Alegre, n.1 v.8, p. 47-55, 2000.

CARVALHO, M. A. F.; MENDONÇA, R. H. (orgs.). Práticas de leitura e escrita. Brasília: Ministério da Educação, 2006.

CAVALCANTE, L. E. Políticas de formação para a competência informacional: o papel das universidades. Revista Brasileira de Biblioteconomia e Documentação: Nova Série, São Paulo, v. 2, n. 2, p. 47-62, dez. 2006.

CRUZ, P.; MONTEIRO, L. (orgs.) Anuário Brasileiro da Educação Básica 2013. São Paulo: Ed. Moderna, 2013.

DIONÍSIO, M. L. A Construção Escolar de Comunidade de Leitores. Leituras do Manual de Português, Coimbra: Livraria Almedina, 2000.

FAILLA, Z. (Org.). Retratos da leitura no Brasil. São Paulo: Imprensa Oficial do Estado de São Paulo: Instituto Pró-Livro, 2012. 344p.

FREIRE, P. A importância do ato de ler. Marisa Lajolo (org.) São Paulo: Moderna, 2003. 
GASQUE, K. C. G. D.. Arcabouço conceitual do letramento informacional. Ciência da Informação, Brasília, v.39, n.03, 2010.

IBGE - INSTITUTO BRASILEIRO DE GEOGRAFIA E ESTATÍSTICA. Indicadores sociais municipais: uma analise dos resultados do universo do censo demográfico 2010. Rio de Janeiro: IBGE, 2011. Disponível em: $<$ https://ww2.ibge.gov.br/home/estatistica/populacao/censo2010/indicadores so ciais municipais/default indicadores sociais municipais.shtm>. Acesso em: 27 mai. 2016.

INEP - INSTITUTO NACIONAL DE ESTUDOS E PESQUISAS EDUCACIONAIS ANÍSIO TEIXEIRA Programa Internacional de Avaliação de Alunos (Pisa): Resultados Nacionais - Pisa 2009. Brasília: O Instituto, 2012. Disponível em: $<$ http://download.inep.gov.br/acoes internacionais/pisa/resultados/2009/brasil $r$ elatorio nacional PISA 2009.pdf>. Acesso em: 27 mai. 2016.

JUSTINO, D. Insucesso escolar: Remediar ou prevenir? IN: ALVES, J. M.; MOREIRA, L. (orgs.), Projecto Fénix: As Artes do Voo e as Ciências da Navegação. Porto: Universidade Católica, 2012.

KATO, M. A. No mundo da escrita: uma perspectiva psicolingüística. 2. ed. São Paulo: Ática, 1986.

LAJOLO, M. Do mundo da leitura para a leitura do mundo. São Paulo: Ática, 2010.

MASLOW, A. Uma teoria da motivação humana. In: BALCÃO, Yolanda F.; CORDEIRO, Laerte L. O comportamento humano na empresa - uma antologia. Rio de Janeiro: Fundação Getúlio Vargas, 1971. p. 340-355.

MENEGASSI, R. J.; ANGELO, C. M. P. Conceitos de leitura. In: MENEGASSI, R. J. (Org.). Leitura e ensino. Maringá: Eduem, 2005. (Formação de professores EAD, n.19).

MORESI, E. A. D. Delineando o Valor do Sistema de Informação de uma Organização. Ciência da Informação, Brasília, v. 29, n. 1, p.14-24. jan/abr. 2000.

OCDE - Organização para Cooperação e Desenvolvimento Econômico.

Relatório Nacional PISA 2012: Resultados Brasileiros. Fundação Santillana:

São Paulo, 2013. ISBN 978-85-63489-17-3. Disponível em: < $<$ http://download.inep.gov.br/acoes internacionais/pisa/resultados/2014/relatori o nacional pisa 2012 resultados brasileiros.pdf>. Acesso em: 25 mai. 2016. 
RIBEIRO, V. M. Alfabetismo funcional: Referências conceituais e metodológicas para pesquisa. Educação \& Sociedade, ano XVIII, n. 60, p. 144-158, dez. 1997.

RIOS, T. A. Ética e competência. 7. ed., São Paulo: Cortez, 1999.

SILVA, E. T. De olhos abertos: reflexões sobre o desenvolvimento da leitura no Brasil. 2.ed. São Paulo: Ática, 1999. 128p.

SILVA, I. M. W. et al. Prática da leitura: problemas e perspectivas. Cadernos de Biblioteconomia, Recife, n.6, p.28-34, jan. 1983.

SOARES, M.. Alfabetização e letramento na educação infantil. Pátio Educação Infantil, Rio Grande do Sul, v. 7, n. 20, p. 6-9, jul./out. 2009.

SOARES, M. Letramento/Analfabetismo. Presença Pedagógica. v. 2, n.10, jul/ago. 1996. p. 83-89.

SOARES, M. Letramento e alfabetização: as muitas facetas. Revista Brasileira de Educação, n. 25, jan/fev/mar/abr 2004, p. 5-17.

SOARES, M. Letramento: um tema em três gêneros. 2.ed. Belo Horizonte: Autêntica, 2004b.

UNESCO. Educação de Adultos: Declaração de Hamburgo; agenda para o futuro. (V Conferência Internacional de Educação de Adultos CONFINTEA V Hamburgo, Alemanha 14-18 de Julho de 1997). UNESCO: Brasília, 1998.

WEINBERG, M.; EDWARD, J. Na trilha coreana. Revista Veja, São Paulo: Editora Abril, ano 38, n.7, p.72, 16 fev. 2005.

WITTER, G. (Org.). Leitura e universidade. Campinas, SP: Editora Alínea, 1997.

\section{Title}

Reading and information literacy in the university: a gap, a fragmented construct or a dilemma?

\section{Abstract:}

Introduction: Since the creation of the expression information literacy in the American educational scenario in 1974, we see the different modifications in its characteristics due to its evolution and application over the years. Despite the different names that the new concept gained here, truth is that its meaning and application find it difficult to fulfill its purpose. The transposition of the concept into a different scenario from where it was originally conceived should outweigh the economic, social and educational difference of realities. Methodology: The article was based on a thorough literature review of work already undertaken in the education area on the matter of reading and, in the 

fragmentado ou um dilema?

area of information science, on information literacy. Results and Conclusions: Reading is the main pillar of information literacy and is also its main barrier that prevents its full implementation in the Brazilian context. The reading problem affects the individual from the elementary levels of education to university, where its lack is viscerally perceived. The inseparability of "alphabetization" and literacy concepts should enable an extension of meanings that would ensure the achievement of information literacy. In fact, the results observed in the reality of surveyed indexes reveal that there is a missing piece in this equation that the information literacy seems unfit to bare.

Keywords: Alphabetization.Literacy. Information literacy. Reading.

\section{Titulo}

La lectura y la alfabetización informacional en la universidad: una brecha, una construcción fragmentada o un dilema?

\section{RESUMEN:}

Introducción: Desde la creación de la expresión alfabetización informacional en el escenario educativo estadounidense en 1974, observamos varios cambios en sus características debido a la evolución y la aplicación a través de los años. A pesar de los diferentes nombres que el nuevo concepto ganó aquí, es verdad que su significado y aplicación tienen dificultades para cumplir su propósito. La transposición del concepto en un escenario diferente de donde fue concebida originalmente debe sopesar las diferentes realidades económicas, sociales y educativas. Metodología: El artículo se basa en una revisión exhaustiva de la literatura de la labor ya realizada en el área de la educación en la lectura de la materia y en el área de ciencias de la información sobre la alfabetización informacional. Resultados Y Conclusiones: La lectura es el pilar principal de la alfabetización informacional y es también su principal barrera que impide su plena aplicación en el contexto brasileño. El problema con la lectura afecta al individuo desde los niveles elementales de la educación hasta la universidad, en los que su falta se percibe visceral. La inseparabilidad de los conceptos de alfabetización y "literacy" deberia habilitar una extensión de significados que aseguraría el logro de la alfabetización informacional. En verdad los resultados observados en la realidad de los índices estudiados revelan que hay una pieza que falta en esta ecuación que la alfabetización informacional parece comportarse.

Palabras clave: Alfabetización. Alfabetizado. Alfabetización informacional. Lectura.

Recebido em: 27.07.2016

Aceito em: 13.12.2017 